\title{
The Economics of Joint Ventures in Centrally Planned and Labor-Managed Economies ${ }^{1}$
}

\author{
Jan Svejnar and Stephen C. SMith \\ Department of Economics, Cornell University, Ithaca, New York 14853 \\ Received April 29, 1981; revised November 1981
}

\begin{abstract}
Svejnar, Jan, and Smith, Stephen C.-The Economics of Joint Ventures in Centrally Planned and Labor-Managed Economies.

The paper analyzes the allocational and distributional issues connected with the operation of joint ventures by firms in Yugoslavia, several Eastern European countries and the People's Republic of China with Western firms. A variable-bargainingpower model is used to examine the behavior of joint ventures under the various institutional circumstances of these countries. Contrary to Brada's conclusions ( $J$. Comp. Econ. 1(2):167-181, June 1977), the present study indicates that the behavior of joint ventures in most of these countries is likely to be quite similar. $J$. Comp. Econ., June 1982, 6(2), pp. 148-172. Cornell University, Ithaca, New York 14853.
\end{abstract}

Journal of Economic Literature Classification Numbers: 053, 442, 514.

\section{INTRODUCTION}

The last few decades have witnessed a continuous growth of the so-called transnational corporations, which engage in production and/or trade beyond the boundaries of their home country. Some of these corporations have begun operating in Yugoslavia, Romania, Hungary, Bulgaria, Poland, and the People's Republic of China under a system of joint ventures, which we define, following Tomlinson (1970), as a "commitment, for more than a very short duration, of funds, facilities, and services by two or more legally separate interests, to an enterprise for their mutual benefit."

In a recent article in this Journal, Josef Brada (1977a) provided a pioneering theoretical treatment of the systems of joint ventures between Western firms and national enterprises in Hungary, Romania, and $\mathrm{Yu}$ -

\footnotetext{
'The authors would like to thank Saul Estrin, two anonymous referees, and members of the Cornell Workshop on the Economics of Participation and Labor-Management for helpful comments.
} 
goslavia. He sought to show that the profit-maximizing objectives of Western firms and the objectives of their domestic partners in joint ventures differed and, as a result, that disagreements over the pricing of inputs and their levels of utilization would occur in joint-venture negotiations. A part of the divergence in objectives stems, according to Brada, from the fact that the socialist partner benefits both from its share of the accounting profits (total revenues minus total costs) of the joint venture and from the sale of inputs to the joint venture at transfer prices above cost. In the negotiation on the operation of the venture the domestic partner thus has an incentive to seek overutilization of those of its resources which are sold to the joint venture at above-cost transfer prices.

Brada (1977a) does not explain how this conflict between the partners is resolved. In fact, Brada's results stem entirely from an analysis in which each partner's criteria for resource allocation are considered separately, rather than in a framework of strategic interaction. This leads to serious shortcomings which we point out in Section $2 .^{2}$

The main aim of this paper is to explain, by means of game theory, how the conflicts between the partners are resolved in terms of resource allocation and income distribution. We start our analysis by recognizing that the partners who jointly form the venture also jointly determine the policies for factor allocation and income distribution. From a bargaining point of view, all partners are therefore interested in the utility they can derive from the venture and in allocating resources so as to maximize their goals.

We generalize Brada's framework by assuming that the Western partner may also benefit from selling some inputs to the joint venture above cost. This is consistent with much of the literature on transnational corporations. In analyzing the various systems of joint ventures we use Svejnar's (1977, 1982) generalization of the Nash (1950) model to account for the bargaining power of the partners. The model presumes that, if the partners are free to bargain, they jointly select a solution that is Pareto-efficient from their perspective and distributes the net income in proportion to their bargaining powers. In analyzing the general framework and applying it to the institutional settings of the several centrally planned and labor-managed economies, we concentrate on the prototypical models of "Romania," "Hungary," and "Yugoslavia." As can be seen from Table 1, the institutional systems in the other countries represent combinations or only minor modifications of these three models. Our analysis shows that:

\footnotetext{
${ }^{2}$ Brada employs an analogous strategy and obtains similar results in a companion (1977b) paper. However, in the latter part of that paper he suggests that a game-theoretic approach to the analysis of input allocation in the joint venture may be more appropriate. Outlining the Nash (1950) two-party bargaining model and the Harsanyi-Selten generalization of the Nash model, Brada claims (but does not prove) that joint ventures can in fact be expected to utilize all inputs Pareto-efficiently.
} 
(i) The factor allocation of the joint venture may, but need not, be socially optimal (in the Pareto sense) from the host country's point of view.

(ii) The achievement of this social allocational optimality depends on the objective functions of the partners, but not in Brada's sense. Rather, socially inefficient resource allocation may emerge in certain types of labormanaged systems because of the objective function of the domestic partner.

(iii) If the joint venture generates a socially inefficient factor allocation, then its extent is directly related to the relative bargaining power of the partners and to the net profit of the venture.

(iv) Even if the host government determines unilaterally the distribution of accounting profits, the partners still divide actual profits in proportion to their true bargaining powers so long as at least one input (transfer) price is subject to bargaining.

(v) With the possible exception of Yugoslavia and perhaps China, a tendency to view Western experiences in these countries within a common framework is not as erroneous as Brada (1977a) suggested. In particular, there is no reason to distinguish between the "Romanian" and "Hungarian" type models in terms of criteria for factor allocation and income distribution.

\section{MODELS OF JOINT VENTURES}

In this section we first discuss Brada's results and point out certain problems associated with his conclusions about the patterns of input utilization sought by each of the partners. In doing so we utilize a more general analytical framework than was used by Brada (1977a). In the second part of this section we outline a bargaining model that appears to be more appropriate for analyzing the allocational and distributional problems of the joint ventures. In Section 3 we apply the model to the institutional frameworks of Romania, Hungary, and Yugoslavia, and compare our results with those of Brada.

Following Brada's (1977a) notation, consider a general model in which the joint venture located in a host country produces one output, $Q$, with the aid of $m$ inputs provided by the Western partner, $X=\left(X_{1}, \ldots, X_{m}\right)$, $n$ nonlabor inputs purchased domestically, $Y=\left(Y_{1}, \ldots, Y_{n}\right)$, and the labor input, $L$, which is also hired in the host country: ${ }^{3}$

$$
Q=Q\left(X_{1}, \ldots, X_{k}, \ldots, X_{m}, Y_{1}, \ldots, Y_{l}, \ldots, Y_{n}, L\right) .
$$

The production function in (1) is assumed to be strictly concave in the relevant range. The output is sold at a fixed price, $P$, (the model is readily generalizable to imperfect competition) and inputs $X$ and $Y$ are acquired

\footnotetext{
${ }^{3}$ The model can be generalized to account for a multiproduct firm without affecting the results presented in this paper. See Laitinen (1980) and Svejnar (1982).
} 

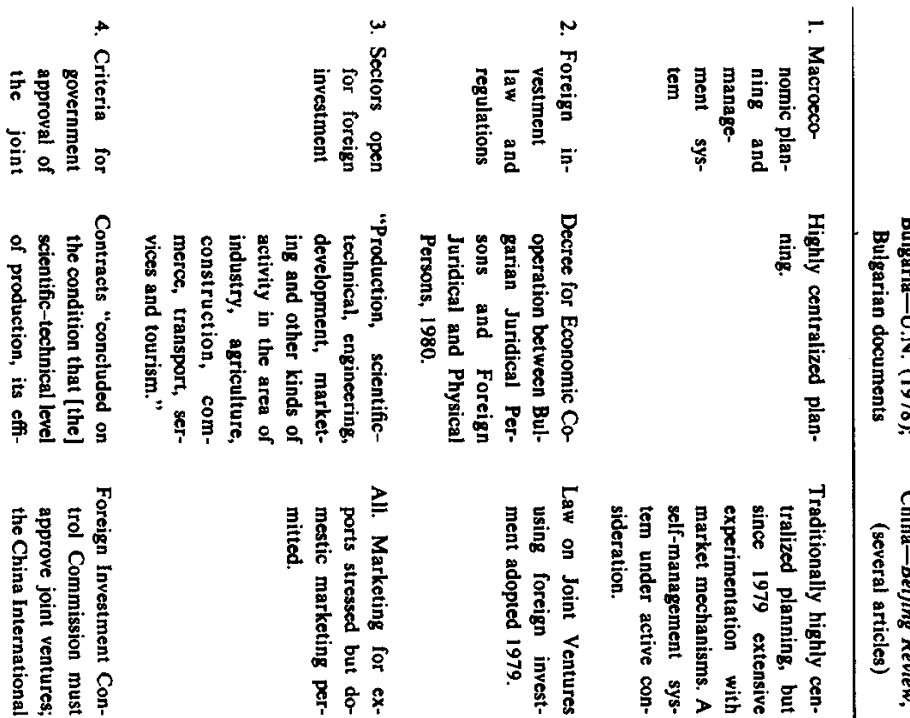

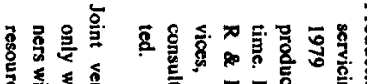

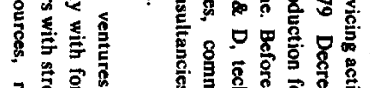





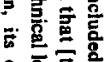

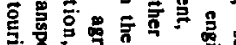

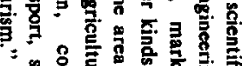

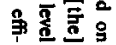

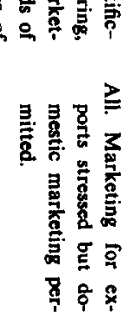

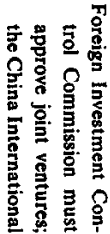

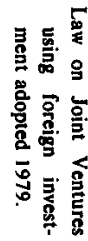

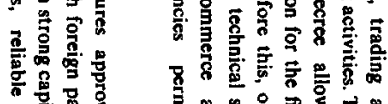

与兽兽

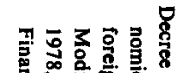



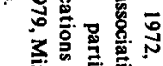

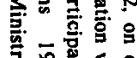

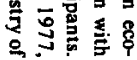

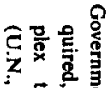

总焉

元窝

है. 遌

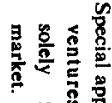

จ

응

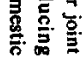

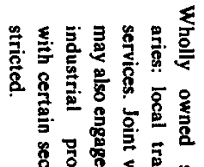



政



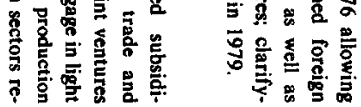

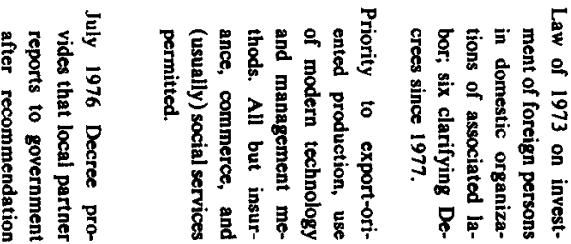
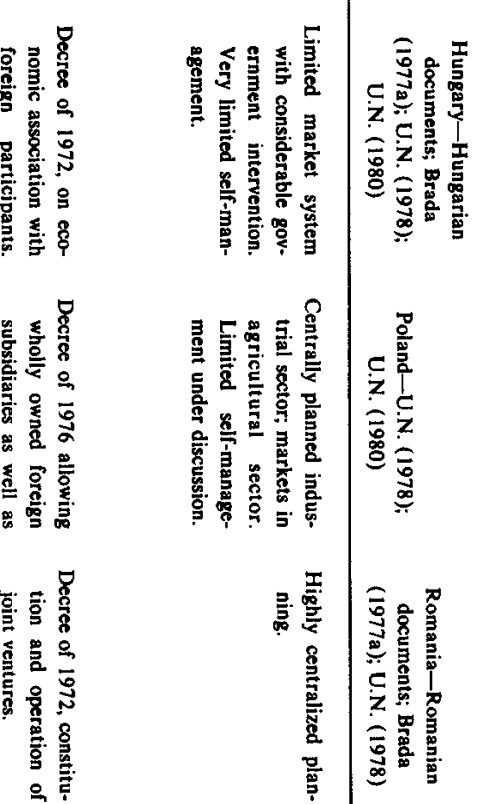

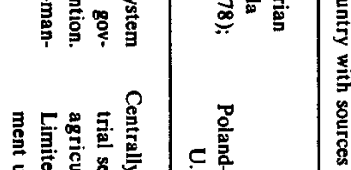






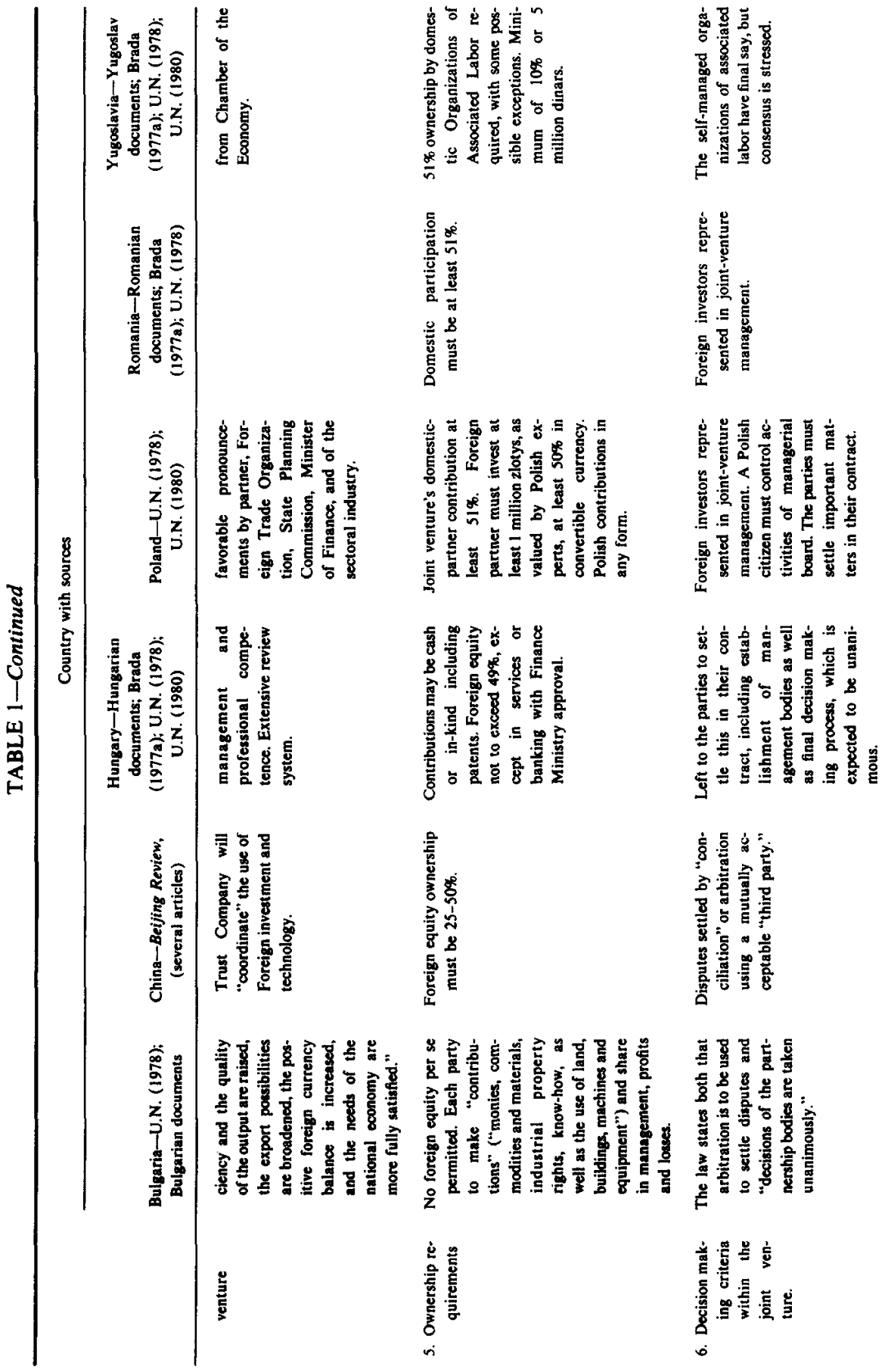



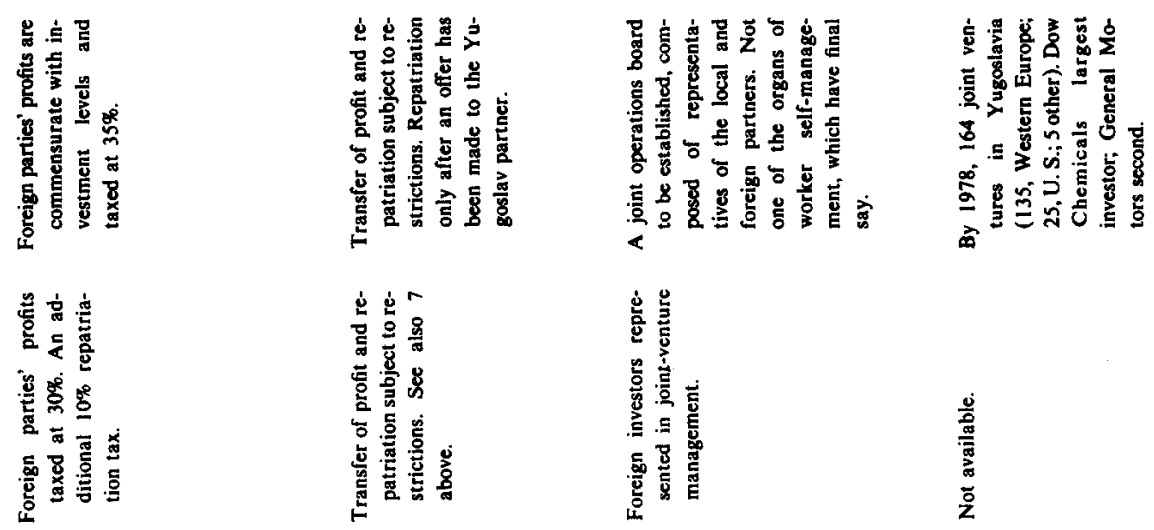

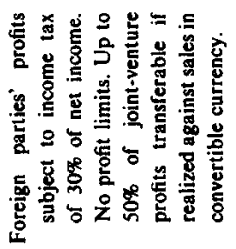
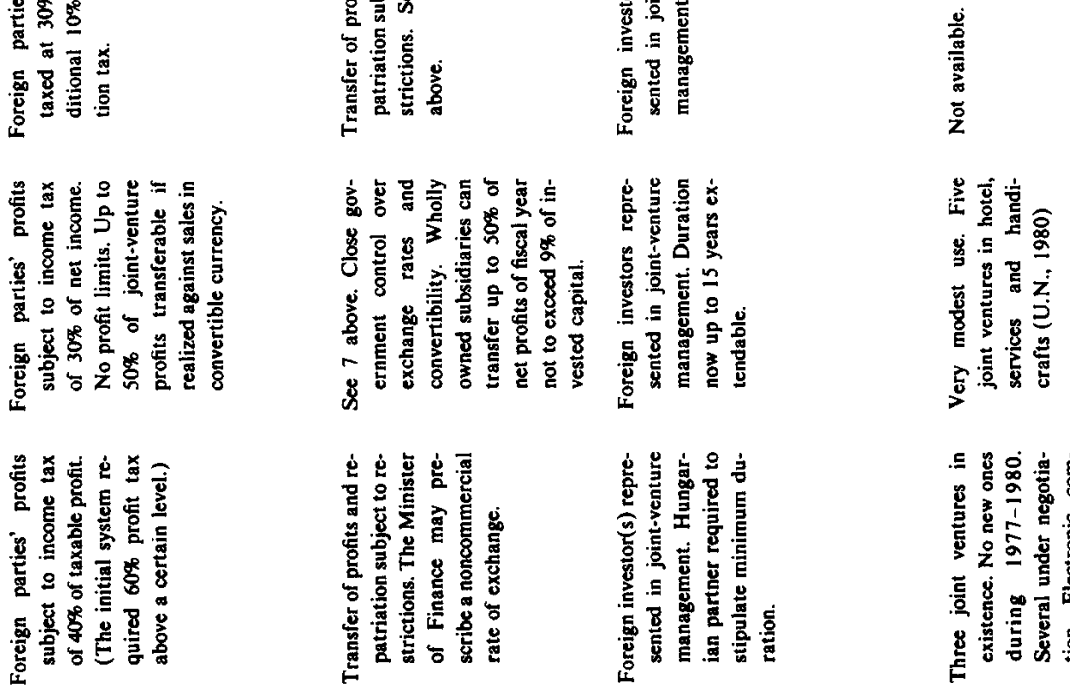



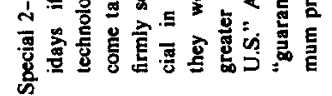





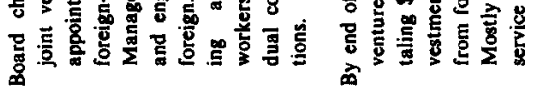
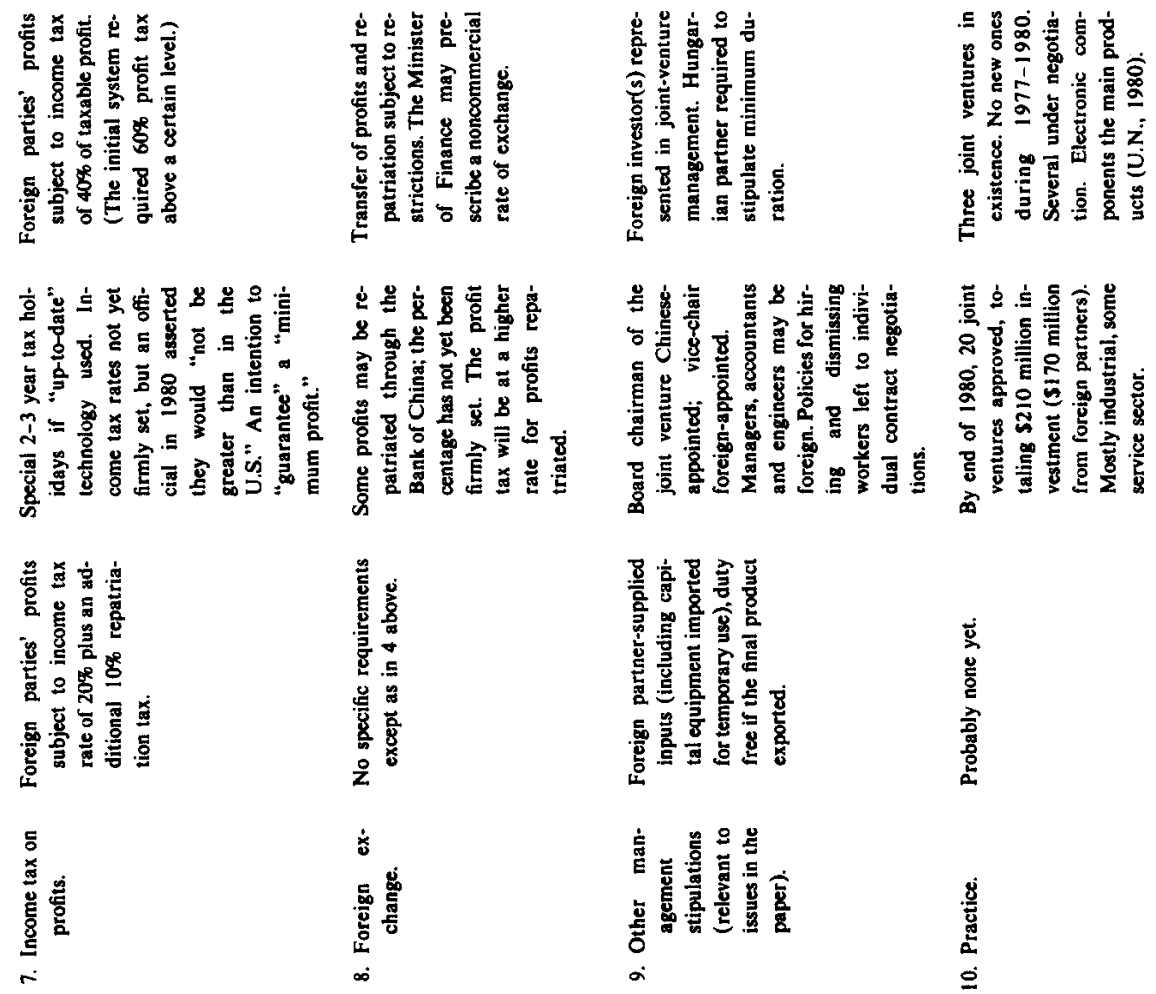



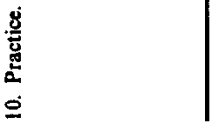


by the respective partners at constant per unit costs $C_{i}(i=1, \ldots, k$, $\ldots, m)$ and $C_{j}^{*}(j=1, \ldots, l, \ldots, n)$. We also assume that each party may exercise a certain discretion over the prices at which it supplies some of its inputs to the joint venture. Brada (1977a) argued that the Western partner's ability to benefit from sales to the joint venture is sharply limited, since Western inputs "must, by virtue of the location of the joint venture, be tradeables and thus their prices can be ascertained from world markets." " Furthermore, it may be argued that partners can obtain quotations from other Western firms in order to determine the going price for a Western input.

The problem with this view is that one of the most common Western inputs is technical and managerial human capital, which is sufficiently project-specific and cost-hidden to leave enormous leeway in determining its market price. Moreover, price quotations for many other inputs are not easily obtainable or, since international competition between the transnational corporations is limited, may carry little information value (see, for example, Barnet and Muller, 1974; Hymer, 1970, 1979). Thus, in our view a more realistic scenario is one where the parties bargain over the prices of some inputs supplied by both of them. ${ }^{5}$

In order to make these concepts operational, we assume that the price vectors $\left(V_{1}, \ldots, V_{k}\right)$ and $\left(W_{1}, \ldots, W_{l}\right)$, which the joint venture actually pays for the first $k$ of the $X$ inputs, $\left(X_{1}, \ldots, X_{k}\right)$, and the first $l$ of the $Y$ inputs, $\left(Y_{1}, \ldots, Y_{l}\right)$, are subject to bargaining between the partners. The other input prices are not subject to bargaining and are equal to the costs of the respective inputs. In particular, for the remaining $m-k$ inputs of $X$ the prices paid by the joint venture are $V_{i}=C_{i}(i=k+1, \ldots, m)$, while $W_{j}=C_{j}^{*}(j=l+1, \ldots, n)$ for the remaining $n-l$ inputs of $Y$. Without loss of generality the price of labor, $P_{\mathrm{L}}$, is at present also assumed to be given parametrically. Usually, the host government contractually allows the Western partner to appropriate a fixed share $s(0 \leq s \leq 1)$ of the firm's accounting profit, $P Q-V X-W Y-P_{\mathrm{L}} L$. The Western partner may then be assumed to maximize

$$
\pi=\sum_{i=1}^{k}\left(V_{i}-C_{i}\right) X_{i}+s\left(P Q-V X-W Y-P_{\mathrm{L}} L\right),
$$

where $\pi$ is the total profit accruing to the Western partner, $V X=\sum_{i=1}^{m} V_{i} X_{i}$

\footnotetext{
${ }^{4}$ Brada, 1977a, p. 170.

${ }^{5}$ This is consistent with much of the institutional literature on transnational corporations; all of our results carry over to the more restricted framework used by Brada (1977a). For a more detailed discussion, see Svejnar and Smith (1981) and Smith (1980).
} 
and $W Y=\sum_{j=1}^{n} W_{j} Y_{j}$. A similar objective function, $\pi^{*}$, can also be constructed for the domestic partner (firm or government),

$$
\pi^{*}=\sum_{j=1}^{l}\left(W_{j}-C_{j}^{*}\right) Y_{j}+(1-s)\left(P Q-V X-W Y-P_{\mathrm{L}} L\right),
$$

where $\pi^{*}$ is the total profit accruing to the domestic partner.

Objective functions (2) and (3) are perfectly analogous to the Romanian objective function postulated by Brada (1977a, p. 171) and the transideological enterprise model employed by Brada (1977b, pp. 445-447). However, while these functions are suitable maximands in the framework of joint decision making which we examine presently, they are not appropriate for analyzing the separate behavioral patterns of the two parties as was done by Brada in both of his papers. In particular, differentiating (3) with respect to $X_{i}$ and $Y_{j}$, Brada obtains the domestic partner's first-order profitmaximizing conditions, which imply

$$
\begin{array}{cl}
P Q_{X_{i}}=V_{i}, & i=1, \ldots, m, \\
P Q_{Y_{j}}=W_{j}-\frac{W_{j}-C_{j}^{*}}{1-s}, & j=1, \ldots, l, \\
W_{j}, & j=l+1, \ldots, n,
\end{array}
$$

with $Q_{X_{i}}$ and $Q_{Y_{j}}$ representing the partial derivatives of $Q$ with respect to $X_{i}$ and $Y_{j}$, respectively.

A similar exercise performed with respect to (2) generates the resourceallocation conditions desired by the Western partners:

$$
\begin{aligned}
P Q_{X_{i}}= & V_{i}-\frac{V_{i}-C_{i}}{s}, & & i=1, \ldots, k, \\
& V_{i}, & i & =k+1, \ldots, m, \\
P Q_{Y_{j}} & =W_{j}, & j & =1, \ldots, n .
\end{aligned}
$$

The two sets of conditions for factor allocation are clearly different and Brada $(1977 \mathrm{a}, \mathrm{b})$ concludes that the partners will disagree on the appropriate levels of inputs and output. Moreover, given that $V_{i}>C_{i}(i=1$, $\ldots, k)$ and $W_{j}>C_{j}^{*}(j=1, \ldots, l)$, Brada (1977a) asserts that the input decisions by both partners will be suboptimal.

One problem with Brada's approach is that one cannot derive results about the respective allocational criteria of the two partners on the basis of functions such as (2) or (3). To see this, take Eq. (3) as the maximand of the domestic partner with $V$ and $P_{\mathrm{L}}$ given parametrically. Unless $s$ $=0$, the domestic partner has an incentive to raise the prices of those in- 
puts whose supply it controls, taking its profit in the form of higher input prices rather than as a share $(1-s)$ of declared profit. Assuming that the declared profit cannot be negative, $P Q-V X-W Y-P_{\mathrm{L}} L \geq 0$, the domestic partner obtains the highest profit for itself by maximizing $P Q-V X$ - $C^{*} Y-P_{\mathrm{L}} L$ but "charging" the firm input prices $W_{j}$ for $X_{j}(j=1$, $\ldots, l)$ such that $P Q-V X-W Y-P_{\mathrm{L}} L=0$. In the extreme, if the declared profit were not institutionally bounded from below, the input prices $W_{j}(j=1, \ldots, l)$ and hence the domestic partner's profit (the Western partner's loss) could be raised to infinity. These conclusions follow from the simple fact that for $s>0$ the objective function (3) is homogeneous of a positive degree in $W_{j}(j=1, \ldots, l)$ and $W_{j}$ is presumed to be under the control of the domestic partners. Analogous reasoning applies with respect to (2), the objective function of the Western partner.

The important point to be derived from these corrections of Brada's approach is that, under the usual assumption of nonnegative net profit, $P Q$ $-V X-W Y-P_{\mathrm{L}} L \geq 0$, the profit maximizing behavior of the two parties, modeled in isolation, leads to the maximization of

$$
\hat{\pi}=P Q-C X-W Y-P_{\mathrm{L}} L
$$

and

$$
\hat{\pi}^{*}=P Q-V X-C^{*} Y-P_{\mathrm{L}} L,
$$

respectively, where $\left(2^{\prime}\right)$ is the maximand of the Western partner and $\left(3^{\prime}\right)$ the maximand of the host. The intuition behind $\left(2^{\prime}\right)$ and $\left(3^{\prime}\right)$ is as follows. As in (2) and (3), each party takes the prices over which it has no discretion as given. It then forms a profit function contingent on these prices and the cost of acquiring the inputs it supplies to the joint venture. The profit function $\hat{\pi}\left[\hat{\pi}^{*}\right]$ measures the maximum profit that the Western partner [the host] can generate from the joint venture by setting $V_{i}(i=1, \ldots$, $k)\left[W_{j}(j=1, \ldots, l)\right]$ so that $P Q-V X-W Y-P_{\mathrm{L}} L=0$. The corresponding first-order conditions for a maximum imply

$$
\begin{aligned}
P Q_{X_{i}} & =C_{i}, \quad i=1, \ldots, m, \\
P Q_{Y_{j}} & =W_{j}, \quad j=1, \ldots, n, \\
P Q_{\mathrm{L}} & =P_{\mathrm{L}}
\end{aligned}
$$

in the case of a Western partner and

$$
\begin{aligned}
& P Q_{x_{i}}=V_{i}, \quad i=1, \ldots, m, \\
& P Q_{Y_{j}}=C_{j}^{*}, \quad j=1, \ldots, n, \\
& P Q_{\mathrm{L}}=P_{\mathrm{L}}
\end{aligned}
$$


in the case of a domestic partner. As these conditions for factor allocation indicate, both partners, acting separately, would use the same marginalproduct criteria (though not the same prices) for allocating resources. The points of disagreement (and hence bargaining) are thus the factor prices $V_{i}(i=1, \ldots, k)$ and $W_{j}(j=1, \ldots, l)$.

While Eqs. $\left(2^{\prime}\right)$ and $\left(3^{\prime}\right)$ indicate that each partner wishes to maximize the net profit of the firm, the corresponding first-order conditions make it clear that in forming and operating the joint venture the partners must agree on the factor prices $V_{i}(i=1, \ldots, k)$ and $W_{j}(j=1, \ldots, l)$, which are subject to bargaining. In order to model both the allocational and distributional aspects of joint-venture behavior, it is therefore inadequate to consider the respective behavior of the two partners in isolation. Rather, it is necessary to use a model that captures the strategic interaction of the partners in maximizing and distributing the net profit of the firm. In this paper we employ a game-theoretic (bargaining) model that allows us to explain these aspects of joint-venture behavior.

\section{The Bargaining Model}

In analyzing the allocational and distributional issues of joint ventures we employ the variable-bargaining-power model developed by Svejnar $(1977,1982)$. The model generalizes the Nash (1950) bargaining model by introducing explicitly the bargaining powers of the parties as determinants of the solution. While in the Nash (1950) model the two parties act as if maximizing the product of their utilities,

$$
\operatorname{Max} U^{\prime}=U_{\mathrm{w}} U_{\mathrm{D}},
$$

in the variable-bargaining-power model the parties act as if maximizing the weighted product of their utilities,

$$
\operatorname{Max} U=U_{\mathbf{W}}^{\gamma_{\mathbf{w}}} U_{\mathbf{D}}^{\gamma_{\mathbf{D}}},
$$

where $U_{\mathrm{W}}$ and $U_{\mathrm{D}}$ are Von Neumann-Morgenstern utility functions of the Western and domestic partner, respectively, $\gamma_{w}$ is the bargaining power of the Western partner, and $\gamma_{D}$ is the bargaining power of the domestic partner. Since only relative power matters it is convenient to normalize by setting $\gamma_{w}=\gamma(0 \leq \gamma \leq 1)$ and $\gamma_{D}=1-\gamma$. The objective function can then be written as

$$
U=U_{W}^{\gamma} U_{\mathrm{D}}^{(1-\gamma)} .
$$

Using (4) as the objective function of the joint venture allows Paretoefficient allocation of resources from the private point of view of the partners. Moreover, at the solution the two partners can be shown to divide 
their joint net gain (in utility terms) in proportion to their bargaining powers as long as at least one input price can be bargained over. In terms of our earlier discussion the model thus allows for joint maximization of net profit and also provides a realistic distributional rule.

\section{MODELS OF SPECIFIC INSTITUTIONAL SYSTEMS}

Table 1 summarizes the major institutional features of the six centrally planned and labor-managed economies that permit joint ventures. ${ }^{6}$ While regulations have changed to blur the distinctions between the three countrycases studied by Brada, they remain valid as distinctive types of joint ventures and hence deserve separate study to see if their respective allocative and distributive criteria diverge. The existing systems depicted in the table conform analytically to the four major cases examined below.

\section{The "Romanian-Type" Model}

In view of the Romanian institutional system for joint ventures we assume that the objective functions of the two partners, $U_{\mathrm{W}}$ and $U_{\mathrm{D}}$, are reflected by Eqs. (2) and (3) of the previous section, respectively. Within the variable-bargaining-power framework the joint venture hence acts as if maximizing

$$
\begin{aligned}
U= & \pi^{\gamma} \pi^{*(1-\gamma)}=\left\{\sum_{i=1}^{k}\left(V_{i}-C_{i}\right) X_{i}\right. \\
& +s\left[P Q\left(X_{1}, \ldots, X_{k}, \ldots, X_{m}, Y_{1}, \ldots, Y_{l}, \ldots, Y_{n}, L\right)\right. \\
& \left.\left.-\sum_{i=1}^{m} V_{i} X_{i}-\sum_{j=1}^{n} W_{j} Y_{j}-P_{\mathrm{L}} L\right]\right\}^{\gamma}\left\{\sum_{j=1}^{l}\left(W_{j}-C_{j}^{*}\right) Y_{j}\right. \\
& +(1-s)\left[P Q\left(X_{1}, \ldots, X_{k}, \ldots, X_{m}, Y_{1}, \ldots, Y_{l}, \ldots, Y_{n}, L\right)\right. \\
& \left.\left.\quad-\sum_{i=1}^{m} V_{i} X_{i}-\sum_{j=1}^{n} W_{j} Y_{j}-P_{\mathrm{L}} L\right]\right\}^{(1-\gamma)} .
\end{aligned}
$$

Taking $X, Y, L, V_{i}(i=1, \ldots, k)$, and $W_{j}(j=1, \ldots, l)$ as the decision variables, the first-order conditions for a maximum lead to the following results: ${ }^{7}$

\footnotetext{
${ }^{6}$ According to an embassy official, East Germany also permits joint ventures but so far none have been undertaken. Moreover, only scanty information is available about their regulations.

${ }^{7}$ See the Appendix.
} 


$$
\begin{aligned}
P Q_{x_{i}} & =C_{i}, \quad i=1, \ldots, m, \\
P Q_{Y_{j}} & =C_{j}^{*}, \quad j=1, \ldots, n, \\
P Q_{\mathrm{L}} & =P_{\mathrm{L}}, \\
\pi & =\gamma\left(P Q-C X-C^{*} Y-P_{\mathrm{L}} L\right), \\
\pi^{*} & =(1-\gamma)\left(P Q-C X-C^{*} Y-P_{\mathrm{L}} L\right) .
\end{aligned}
$$

The first three conditions in (5) determine the resource-allocation criteria of the joint venture. They indicate that the partners jointly allocate resources so that the marginal value product of each input equals the corresponding per unit cost of the input. Hence, rather than using transfer prices $V_{i}(i=1, \ldots, k)$ and $W_{j}(j=1, \ldots, l)$, where $V_{i}>C_{i}$ and $W_{j}$ $>C_{j}^{*}$, the joint venture uses the actual acquisition costs of both the Eastern and the Western inputs in determining the optimal levels of input use. This result is important for two reasons: (a) it underscores the joint profit-maximizing nature of the firm and (b) it indicates that the objective functions of the two partners given by (2) and (3) lead to socially efficient allocation of resources. The joint venture operating in a "Romanian-type" institutional system can thus be expected to be Pareto-efficient from the private point of view of the two partners as well as from the social vantage point.

The last two conditions in (5) describe the distributional aspect of the joint venture. Having generated the largest possible net profit, $P Q-C X$ $-C^{*} Y-P_{\mathrm{L}} L$, the partners divide it in proportion to their bargaining powers,

$$
\pi / \pi^{*}=\gamma /(1-\gamma) \text {. }
$$

In harmony with the allocational criteria and the bargaining nature of the relationship, net profit is calculated as the revenues, $P Q$, minus the total factor cost evaluated at the actual supply costs of all inputs, $C X+C^{*} Y$ $+P_{\mathrm{L}} L$.

As the distributional rule in (6) indicates, the relative bargaining powers, $\gamma$ and $1-\gamma$, are the sole determinants of the actual division of the net profit. This of course implies that the contractually set profit shares, $s$ and $1-s$, play no part in the distribution of the net profit between the two partners. While this result may at first seem surprising, it explains why one can observe transnational corporations entering into joint ventures under varying and often seemingly adverse conditions in terms of their contractual share of profit, $s$. The foregoing analysis shows that so long as the transnational corporation supplies inputs whose prices, $V_{i}(i=1$, $\ldots, k)$, are subject to bargaining, its actual share of net profit is determined solely by its relative bargaining power, $\gamma$, and its net profit share, $\pi$, is 
collected through a combination of $s\left(P Q-V X-W Y-P_{\mathrm{L}} L\right)$ and $\sum_{i=1}^{k}\left(V_{i}\right.$ $\left.-C_{i}\right) X_{i}$. The same principle of course applies to the domestic partner.

\section{The "Hungarian Model"}

In the "Hungarian Model" of a joint venture, which was the only type permitted in Hungary from 1972 to 1977 , the domestic partner produces $Q$ under contract to the joint venture. The Western partner contributes the technology, convertible currency, and specialized inputs. The typical venture then sells $Q$ either domestically or abroad.

Appealing to the existence of "at least partially functioning markets in Hungary and a meaningful exchange rate for the Hungarian forint," Brada (1977a) simplifies the analysis by assuming that (a) the Hungarian partner supplies $Q$ to the venture at a negotiated price $P^{\prime},(\mathrm{b})$ there is a cost $D(Q)$ associated with the distribution (sale) of $Q$ by the venture, and (c) the Hungarian partner faces a cost function $C(Q)$ in producing $Q$. In this framework the Western partner is presumably maximizing its share $s$ of the profit given by

$$
\pi=s\left[\left(P-P^{\prime}\right) Q-D(Q)\right] .
$$

Provided $D_{Q}>0$, the profit of the Western partner is maximized when

$$
P-P^{\prime}=D_{Q},
$$

i.e., the constant per unit revenue (mark-up) equals the marginal cost of distributing $Q$.

In contrast, the Hungarian partner's objective function is

$$
\pi^{*}=(1-s)\left[\left(P-P^{\prime}\right) Q-D(Q)\right]+P^{\prime} Q-C(Q),
$$

which is maximized when

$$
(1-s)\left(P-P^{\prime}-D_{Q}\right)+P^{\prime}-C_{Q}=0 .
$$

Brada (1977a) notes that (7) and (8) are identical only "if the transfer price $P^{\prime}$ is set by negotiation at $C_{Q}$ " $\mathrm{He}$ also points out that if $P^{\prime} \neq C_{Q}$ there is a disagreement between the partners regarding the operation of the venture.

In general there is no reason why $P^{\prime}$ should be set equal to $C^{\prime}(Q)$. $P^{\prime}$ is a parameter while $C^{\prime}(Q)$ is a variable whose value changes with the scale of operation. If anything, one might argue that the Hungarian firm adjusts $Q$ so as to achieve $C^{\prime}(Q)=P^{\prime}$. However, Brada's model is not formulated to produce this result and the outcome $C^{\prime}(Q)=P^{\prime}$ is purely coincidental. 
Definite results can be obtained using the variable-bargaining-power model given by (4). In that framework the partners act as if maximizing

$$
\begin{aligned}
U=\pi^{\gamma} \pi^{*(1-\gamma)} & =\left\{s\left[\left(P-P^{\prime}\right) Q-D(Q)\right]\right\}^{\gamma} \\
& \times\left\{(1-s)\left[\left(P-P^{\prime}\right) Q-D(Q)\right]+P^{\prime} Q-C(Q)\right\}^{(1-\gamma)} .
\end{aligned}
$$

Taking $Q$ and $P^{\prime}$ as the decision variables, the first-order conditions corresponding to this maximization problem lead to ${ }^{8}$

$$
\begin{aligned}
P & =C_{Q}+D_{Q}, \\
\pi & =\gamma[P Q-C(Q)-D(Q)], \\
\pi^{*} & =(1-\gamma)[P Q-C(Q)-D(Q)] .
\end{aligned}
$$

The first equation in (9) reflects the allocational criterion of the joint venture. Resources are allocated so that the sum of the marginal cost of production plus distribution, $C_{Q}+D_{Q}$, equals the parametrically given output price, $P$. This criterion of course makes sense as it generates maximum profit for the joint venture. The equation also implies that if $P^{\prime}$ $=C_{Q}$ then $P-P^{\prime}=D_{Q}$ as Brada (1977a) found in his model. However, the present model also indicates that there is no reason why $P^{\prime}=C_{Q}$ or $P-P^{\prime}=D_{Q} . P^{\prime}$ is an internal transfer price which is set so as to maximize the net profit of the joint venture and distribute it among the partners in proportion to $\gamma$ and $(1-\gamma)$. As in the Romanian-type model, the distribution of the net profit is hence determined by the relative bargaining power, $\gamma$ and $(1-\gamma)$, and Eq. (6) holds. The contractually set profit shares, $s$ and $(1-s)$, again play no part in the distribution of the net profit.

The 1977 Hungarian law on joint ventures introduced new elements into the relationship between the Western and domestic partners. The Western partners may now supply inputs and otherwise participate in the productive activities of the Hungarian joint ventures. Taking these legal innovations into account, the objective functions of the two partners may be specified as follows, beginning with the Western partner:

$$
\begin{aligned}
& \pi= \sum_{i=1}^{k}\left(V_{i}-C_{i}\right) X_{i}+s\left[\left(P-P^{\prime}\right) Q-D(Q)\right], \\
& \pi^{*}=\sum_{j=1}^{l}\left(W_{j}-C_{j}^{*}\right) Y_{j}+(1-s)\left[\left(P-P^{\prime}\right) Q-D(Q)\right] \\
&+P^{\prime} Q-V X-W Y-P_{L} L .
\end{aligned}
$$

Both of these objective functions are again subject to the production func-

\footnotetext{
${ }^{8}$ These and the following results are derived through the same procedure that generated the "Romanian Model" conditions in the Appendix.
} 
tion given by (1). Within the variable-bargaining-power model the parties act as if maximizing

$$
\begin{aligned}
U=\pi^{\gamma} \pi^{*(1-\gamma)}= & \left\{\sum_{i=1}^{k}\left(V_{i}-C_{i}\right) X_{i}+s\left[\left(P-P^{\prime}\right) Q-D(Q)\right]\right\}^{\gamma} \\
& \times\left\{\sum_{j=1}^{l}\left(W_{j}-C_{j}^{*}\right) Y_{i}+(1-s)\left[\left(P-P^{\prime}\right) Q-D(Q)\right]\right. \\
& \left.+P^{\prime} Q-V X-W Y-P_{\mathrm{L}} L\right\}^{(1-\gamma)},
\end{aligned}
$$

subject to (1). With $V_{i}(i=1, \ldots, k), P^{\prime}, W_{j}(j=1, \ldots, l), X, Y$, and $L$ being the decision variables, the first-order conditions for a maximum lead to the following results:

$$
\begin{aligned}
\left(P-D_{Q}\right) Q_{X_{i}} & =C_{i}, \quad i=1, \ldots, m, \\
\left(P-D_{Q}\right) Q_{Y_{j}} & =C_{j}, \quad j=1, \ldots, n, \\
\left(P-D_{Q}\right) Q_{\mathrm{L}} & =P_{\mathrm{L}}, \\
\pi & =\gamma\left[P Q-C X-C^{*} Y-P_{\mathrm{L}} L-D(Q)\right], \\
\pi^{*} & =(1-\gamma)\left[P Q-C X-C^{*} Y-P_{\mathrm{L}} L-D(Q)\right] .
\end{aligned}
$$

An examination of these conditions reveals that, apart from the terms $D(Q)$ and $D_{Q}$, the allocational and distributional conditions in this "revised Hungarian model" are identical with those in the "Romanian-type model." Should distribution costs, $D(Q)$, be explicitly taken into account in the "Romanian-type model" the results would be identical. Consequently, there is no reason to distinguish the two models in terms of criteria for factor allocation and income distribution.

\section{The "Yugoslav Model"}

The Yugoslav system of workers' self-management generates a new objective function for the domestic (Yugoslav) partner. Following the models of Ward (1958), Domar (1966), and Vanek (1970), Brada (1977a) assumes that the Yugoslav worker-managers will maximize the income per worker, where relevant workers are those remaining with the firm after the optimum resource allocation has been reached. Utilizing his Romanian-type objective function for the Western partner, Brada (1977a) shows that, as in the Romanian model, the Western partner wishes to allocate resources so that for each input the value of marginal product equals the parametrically given input price. The Yugoslav worker-managers have the same criterion for the nonlabor inputs. However, as in the Ward-Domar-Vanek model, the worker-managers wish to equate the marginal value product of labor 
to the actual income per worker. Formally, the Western partner's objective function

$$
\pi=s\left(P Q-V X-W Y-P_{\mathrm{L}} L\right)
$$

gives rise to the following resource-allocation conditions:

$$
\begin{aligned}
P Q_{X_{i}} & =V_{i}, \quad i=1, \ldots, m, \\
P Q_{Y_{j}} & =W_{j}, \quad j=1, \ldots, n, \\
P Q_{\mathrm{L}} & =P_{\mathrm{L}} .
\end{aligned}
$$

The Yugoslav worker-managers maximize

$$
\pi^{*}=P_{\mathrm{L}}+\frac{1-s}{L}\left(P Q-V X-W Y-P_{\mathrm{L}} L\right)
$$

and they wish to allocate resources according to the following criteria:

$$
\begin{aligned}
P Q_{X_{i}} & =V_{i}, \quad i=1, \ldots, m, \\
P Q_{Y_{j}} & =W_{j}, \quad j=1, \ldots, n, \\
P Q_{\mathrm{L}} & =P_{\mathrm{L}}+\left(P Q-V X-W Y-P_{\mathrm{L}} L\right) / L .
\end{aligned}
$$

Brada (1977a) points out that if profit is positive, $P Q-V X-W Y$ $-P_{\mathrm{L}} L>0$, the two partners disagree on the criterion for the utilization of labor, and, assuming that marginal products of other inputs are functions of the volume of labor employed, the two partners in fact disagree on the actual utilization of all inputs.

There is another source of conflict arising between the two partners, namely the division of workers' incomes into wages, $P_{\mathrm{L}}$, and the profit share, $(1-s)\left(P Q-V X-W Y-P_{\mathrm{L}} L\right) / L$. While in his formal exposition Brada (1977a) treats $P_{\mathrm{L}}$ as given, he argues correctly that if $P_{\mathrm{L}}$ is increased by one dinar the Yugoslav workers gain $s$ dinars at the expense of the foreign partner. Since this is a crucial aspect of the joint venture which is not found in the standard Ward-Domar-Vanek model of a labor-managed firm, it is worthwhile to explore this aspect of the joint venture more formally.

Realizing the problems inherent in examining the objectives of the two partners in isolation, we model the Yugoslav-type joint venture within the variable-bargaining-power model. We use the more general framework in which the objective function of the Western partner is

$$
\pi=\sum_{i=1}^{k}\left(V_{i}-C_{i}\right) X_{i}+s\left(P Q-V X-W Y-P_{\mathrm{L}} L\right),
$$

while the Yugoslav worker-managers maximize 


$$
\pi^{*}=\frac{1}{L}\left[\sum_{j=1}^{l}\left(W_{j}-C_{j}^{*}\right) Y_{j}+(1-s)\left(P Q-V X-W Y-P_{\mathbf{L}} L\right)\right],
$$

where $P_{\mathrm{L}}$ is taken as the threat point of a typical worker. The partners then behave as if jointly maximizing

$$
\begin{aligned}
U= & \pi^{\gamma} \pi^{*(1-\gamma)}=\left\{\sum_{i=1}^{k}\left(V_{i}-C_{i}\right) X_{i}+s\left(P Q-V X-W Y-P_{\mathrm{L}} L\right)\right\}^{\gamma} \\
& \times\left\{(1 / L)\left[\sum_{j=1}^{l}\left(W_{j}-C_{j}^{*}\right) Y_{j}+(1-s)\left(P Q-V X-W Y-P_{\mathrm{L}} L\right)\right]\right\}^{(1-\gamma)} .
\end{aligned}
$$

The first-order conditions for a maximum yield the following results:

$$
\begin{aligned}
P Q_{X_{i}} & =C_{i}, \quad i=1, \ldots, m, \\
P Q_{Y_{j}} & =C_{j}^{*}, \quad j=1, \ldots, n, \\
P Q_{\mathrm{L}} & =P_{\mathrm{L}}+\sum_{j=1}^{l} \frac{\left(W_{j}-C_{j}^{*}\right) Y_{j}}{L}+\frac{1-s}{L}\left(P Q-V X-W Y-P_{\mathrm{L}} L\right), \\
\pi & =\gamma\left(P Q-C X-C^{*} Y-P_{\mathrm{L}} L\right), \\
\pi^{*} & =(1-\gamma)\left[\left(P Q-C X-C^{*} Y-P_{\mathrm{L}} L\right) / L\right] .
\end{aligned}
$$

It is also easy to show that if, as in Brada's formulation, the prices of all the nonlabor inputs are given, $W_{i}=C_{i}^{*}(i=1, \ldots, n)$ and $V_{i}=C_{i}$ $(i=1, \ldots, m)$, then

$$
\begin{aligned}
P Q_{X_{i}} & =V_{i}=C_{i}, \quad i=1, \ldots, m, \\
P Q_{Y_{j}} & =W_{j}=C_{j}^{*}, \quad j=1, \ldots, n, \\
P Q_{\mathrm{L}} & =P_{\mathrm{L}}+\frac{1-s}{L}\left(P Q-V X-W Y-P_{\mathrm{L}}\right), \\
\pi & =\gamma\left(P Q-V X-W Y-P_{\mathrm{L}} L\right), \\
\pi^{*} & =(1-\gamma)\left(P Q-V X-W Y-P_{\mathrm{L}} L\right) / L .
\end{aligned}
$$

The first three conditions in $(10)$ and $\left(10^{\prime}\right)$ determine the factor allocation of the joint venture. These conditions indicate that the venture adopts the resource-allocation criteria of the Yugoslav partner. Resources are allocated so that the marginal value products of all nonlabor inputs are equated to the per unit acquisition costs of these inputs. In this respect the Yugoslav joint ventures behave like their Romanian or Hungarian counterparts.

The crucial distinction between the joint ventures in Yugoslavia and in 
the other countries arises from the condition governing the allocation of labor. As the third condition in (10) and $\left(10^{\prime}\right)$ demonstrates, Yugoslavtype joint ventures equate the marginal value product of labor to the actual income per worker, $P_{\mathrm{L}}+\pi^{*}$. Unless $P_{\mathrm{L}}+\pi^{*}$ accidentally happens to equal the economy-wide full-employment income per worker, the actual allocation of resources by any given joint venture is Pareto-inefficient from the social point of view. Qualitatively, this result corresponds to that obtained for a Ward-Domar-Vanek-type labor-managed firm. However, as the last two conditions in (10) and $\left(10^{\prime}\right)$ indicate, the Yugoslav joint ventures behave differently from their domestic labor-managed counterparts in terms of their criteria for income distribution and hence also in terms of their actual resource allocation. In particular, the domestic labor-managed firms do not share their net profit with a foreign partner, $\gamma=0$, and hence are likely to generate different income per worker. ${ }^{9}$ Differences in the actual income per worker imply different allocation of all inputs provided the production function is not additively separable. Under complete separability differences exist merely with respect to allocation of labor; and, assuming identical technology, firms with the highest income per worker will use the least of the labor input.

As our analysis indicates, the joint ventures use the same criteria as the domestic labor-managed firms for factor allocation but, due to differences in the distribution (and possibly the level) of net profit, they are likely to differ in terms of actual resource allocation. Moreover, while both types of firms behave Pareto-efficiently from their private point of view, they are Pareto-inefficient from the social vantage point whenever the net profit is positive.

\section{An Alternative Labor-Management Model}

The "Yugoslav Model" presented in the preceding section generates conclusions that are similar to those of the Ward-Domar-Vanek model of a labor-managed firm. Unfortunately, the two models also share the same unrealistic features that have been criticized by many researchers, including Robinson (1967) and Vanek (1970). In particular, the models assume that a self-managed collective of $\bar{L}$ workers, who wish to remain with the firm, does not maximize an objective function such as income pertaining to these $\bar{L}$ workers. Instead, the models assume that the given group of $\bar{L}$ workers will adjust employment (and if necessary lay off some of its worker-members) so that the income of the workers who remain with the firm (say, $L$ ) is maximized.

No institutional justification is usually provided to motivate this behav-

${ }^{9}$ Of course, differences in income per worker may also exist if the joint ventures use technologies and inputs different from those used in the domestic labor-managed firms. 
ior. It is, therefore, not clear why any given group of $\bar{L}$ workers would agree to an involuntary lay-off of $\bar{L}-L$ of its members, how this adjustment in employment is carried out, what status the laid-off workers retain, and what compensation these workers receive. In the absence of (i) a plausible institutional justification for the maximand of the Ward-Domar-Vanek model, or (ii) sufficient empirical evidence supporting the model, it is possible that labor-managed firms in fact follow other objectives. Indeed, three alternative models of a labor-managed firm have recently been advanced by Sapir (1980), Miyazaki and Neary (1979), and Svejnar (1982), respectively. Each of these models could be used as a basis for analyzing joint-venture behavior in a labor-managed economy. Because of the limited scope of this paper, we merely adapt Svejnar's (1982) model to the case of joint ventures and briefly examine the underlying criteria for resource allocation and income distribution.

The model assumes that while the Western partner again maximizes

$$
\pi=\sum_{i=1}^{k}\left(V_{i}-C_{i}\right) X_{i}+s\left(P Q-V X-W Y-P_{\mathrm{L}} L\right),
$$

the worker-managers maximize the expected income of the $\bar{L}$ worker-members. In this institutional framework the $\bar{L}$ workers strive to maximize their total (or average) labor income from all available sources and allocate their resources accordingly. The framework is compatible with various forms of income distribution (transfers) between the $L$ workers who are at any given time selected to work in the firm and the $\bar{L}-L$ workers who at that time either work elsewhere or consume leisure.

Formally, a typical worker-member faces the probability $L / \bar{L}$ of being employed in the given firm and earning

$$
P_{\mathrm{L}}+\pi^{*}=P_{\mathrm{L}}+\frac{1}{L}\left[\sum_{j=1}^{l}\left(W_{j}-C_{j}^{*}\right) Y_{j}+(1-s)\left(P Q-V X-W Y-P_{\mathrm{L}} L\right)\right],
$$

as well as the probability $1-(L / \bar{L})$ of not working with the firm and earning $P_{\mathrm{L}}{ }^{10}$ The expected income that is being maximized by the workermanagers is hence given by

$$
\left(P_{\mathrm{L}}+\pi^{*}\right) \frac{L}{\bar{L}}+P_{\mathrm{L}}\left(1-\frac{L}{\bar{L}}\right)
$$

Taking $P_{\mathrm{L}}$ as the worker threat point, the two parties within the variablebargaining-power model then act as if maximizing

\footnotetext{
${ }^{10} \mathrm{It}$ is assumed here that $P_{\mathrm{L}}$ is the (best alternative) market wage or the mean of a distribution of the available alternative wages.
} 


$$
\begin{aligned}
U= & \left\{\sum_{j=1}^{k}\left(V_{i}-C_{i}\right) X_{i}+s\left(P Q-V X-W Y-P_{\mathrm{L}} L\right)\right\}^{\gamma} \\
& \times\left\{\frac{1}{\bar{L}}\left[\sum_{j=1}^{l}\left(W_{j}-C_{j}^{*}\right) Y_{j}+(1-s)\left(P Q-V X-W Y-P_{\mathrm{L}} L\right]\right\}^{(1-\gamma)} .\right.
\end{aligned}
$$

The first-order conditions for a maximum corresponding to (4e) yield

$$
\begin{aligned}
P Q_{x_{i}} & =C_{i}, \quad i=1, \ldots, m, \\
P Q_{Y_{j}} & =C_{j}^{*}, \quad j=1, \ldots, n, \\
P Q_{\mathrm{L}} & =P_{\mathrm{L}}, \\
\pi & =\gamma\left(P Q-C X-C^{*} Y-P_{\mathrm{L}} L\right), \\
\pi^{* *} & =(1-\gamma)\left(P Q-C X-C^{*} Y-P_{\mathrm{L}} L\right) / \bar{L},
\end{aligned}
$$

where $\pi^{* *}$ is labor's share of net profit divided by $\bar{L}$. As these conditions indicate, the joint ventures in the present model allocate resources in a socially Pareto-efficient way. All resources are hired to the point where their marginal value products equal their acquisition (market) prices. The two partners again split the net profit in proportion to their bargaining powers and contractual profit shares, $s$ and $(1-s)$, are ineffective.

The important aspect of this model is the independence of the allocative and distributive criteria. Although all decisions are made simultaneously, one may think of the bargaining process as being divided into two stages. First, the partners allocate resources in a privately as well as socially optimal way. Second, they divide the net profit in proportion to their bargaining powers. The separation of the allocative and distributive issues implies that in terms of resource allocation the joint venture and the domestic labor-managed firms are identical so long as they share the same technology, inputs, and market conditions.

The theoretical predictions obtained from the two models of Yugoslavtype joint ventures are substantially different both from the academic and the policy point of view. The next logical area of research is clearly to test which model is better supported empirically.

\section{POLICY IMPLICATIONS}

Our analysis highlights two relevant policy areas. One is the social efficiency of resource allocation in joint ventures. The other is the bargaining process and the relative bargaining powers of the parties.

The issue of social efficiency arises only with respect to participatory or labor-managed joint ventures in which the labor-managed partner repre- 
sents the relatively narrow and changing constituency of workers remaining with the enterprise once the firm reaches a given equilibrium position. ${ }^{11}$ In the expected income-maximizing participatory scheme as well as in all the other cases examined in this paper, the ventures allocate resources Pareto-efficiently from the host country's social point of view. Since many governments consider the introduction of worker participation or self-management, the efficiency implications of the two types of systems ought to be carefully weighed. It must also be remembered that inefficiency arises in the first type of participatory and self-managed firms only when the net profit and labor's bargaining power are positive. The actual industrial structure and the relative strength of the partners are thus relevant factors to be considered in formulating the appropriate policies.

The existing evidence indicates that the distributional issues are among the major ones arising between the two partners. In forming a joint venture each party tries to create institutions and bargaining processes that it regards as most advantageous for itself. In other words, in the situation of a constant-sum game each party attempts to position itself so as to maximize its relative bargaining power.

Given the institutional frameworks surveyed in this paper, there are several options open to each party. In simple terms, there are two stages during which the conflict issues can be resolved. The first stage covers the negotiation of the formal contract while the second one spans the operation of the venture while the formal contract is in force. Some observers contend that all major issues, including the distribution of net profit, can be resolved in the first stage. For example, Dymsza (1972, p. 211) argues that jointventure contracts "can deal with possible conflict areas, such as election of the board of directors, management selection and remuneration, the determination of financial structure, payment for central administrative services, management and technology, and distribution of profits." There is no doubt that the more clearly specified the contract, the less room there is for bargaining in the second stage. At the same time, a realistic approach must recognize that imperfect foresight and changing market (as well as other) conditions make the complete specification of an efficient contract impossible. As Hall and Lilien (1979, p. 870) pointed out in their recent study of efficient wage bargains, "neither party to a collective-bargaining agreement has full knowledge of the economic circumstances that will prevail during the agreement. Both the demand for products and the opportunity cost of labor can change unexpectedly. Framers of agreements must anticipate the possible need to adjust the level of employment as

\footnotetext{
${ }^{11}$ It must be noted that the conclusions regarding social optimality are unambiguously valid only if one assumes that the cost of inputs, $C, C^{*}$, and $P_{\mathrm{L}}$, as well as the product price, $P$, correspond to prices that would generate Pareto-efficient resource allocation in the economy.
} 
supply and demand change." Combining the uncertainty of the parties with Leontief's (1946) classic result that both prices and quantities need to be fully specified by the bargainers if the bargain is to be efficient from their private point of view, one can readily see that bargaining is likely to take place in both stages.

The two-stage negotiation process has important implications for bargaining outcomes within the institutional systems examined in this paper. The "Eastern" partner may be represented by the government, a domestic firm or both. In many situations the host government (usually the finance ministry) provides a significant input into the negotiation of the formal contract while the domestic firm is the primary negotiator in the second stage. The government negotiators are usually more experienced, enjoy access to better information, and command superior bargaining skills and expertise than the negotiators of a domestic firm. This disparity is likely to be reflected in the strategic behavior of a rational foreign partner. The resulting distribution of the net profit will be proportional to the relative bargaining powers of the foreign partner and the domestic firm, $\gamma /(1$ $-\gamma$ ), even if the initial contract reflects the relative bargaining powers of the foreign partner and the host government, $s /(1-s)$. To the extent that the host government supplies its firms with better market information and bargaining expertise during the joint-venture operations, the actual bargaining power of the domestic partner may in fact be enhanced vis à vis the foreign counterpart. Finally, since the results are perfectly symmetric, they apply to the foreign firms as well, provided these firms use different negotiators in the two stages of joint-venture bargaining.

\section{APPENDIX: DERIVATION OF THE RESULTS FOR THE ROMANIAN MODEL}

The firm acts as if maximizing the function

where

$$
U=\pi^{\gamma} \pi^{*(1-\gamma)},
$$

$$
\begin{aligned}
\pi= & \sum_{i=1}^{k}\left(V_{i}-C_{i}\right) X_{i} \\
& \quad+s\left(P Q-\sum_{i=1}^{k} V_{i} X_{i}-\sum_{i=k+1}^{m} C_{i} X_{i}-\sum_{j=1}^{l} W_{j} Y_{j}-\sum_{j=l+1}^{n} C_{j}^{*} Y_{j}-P_{\mathrm{L}} L\right), \\
& \quad \sum^{*}\left(W_{j}-C_{j}^{*}\right) Y_{j} \\
& +(1-s)\left(P Q-\sum_{i=1}^{k} V_{i} X_{i}-\sum_{i=k+1}^{m} C_{i} X_{i}-\sum_{j=1}^{l} W_{j} Y_{j}-\sum_{j=l+1}^{n} C_{j}^{*} Y_{j}-P_{\mathrm{L}} L\right), \\
Q= & Q\left(X_{1}, \ldots, X_{k}, \ldots, X_{m}, Y_{1}, \ldots, Y_{l}, \ldots, Y_{n}, L\right) .
\end{aligned}
$$


For simplicity of differentiation, (A1) can be expressed in natural logarithms as

$$
\hat{U}=\gamma \ln \pi+(1-\gamma) \ln \pi^{*} .
$$

The first-order conditions corresponding to $\left(\mathrm{Al}^{\prime}\right)$ are

$$
\begin{aligned}
& \frac{\partial \hat{U}}{\partial X_{i}}=\frac{\gamma}{\pi}\left(V_{i}-C_{i}+s P Q_{X_{i}}-s V_{i}\right)+\frac{(1-\gamma)(1-s)}{\pi^{*}}\left(P Q_{X_{i}}-V_{i}\right)=0, \\
& i=1, \ldots, k \text {, } \\
& \frac{\partial \hat{U}}{\partial X_{i}}=\frac{\gamma s}{\pi}\left(P Q_{X_{i}}-C_{i}\right)+\frac{(1-\gamma)(1-s)}{\pi^{*}}\left(P Q_{X_{i}}-C_{i}\right)=0, \\
& i=k+1, \ldots, m \text {, } \\
& \frac{\partial \hat{U}}{\partial Y_{j}}=\frac{\gamma s}{\pi}\left(P Q_{Y_{j}}-W_{j}\right)+\frac{(1-\gamma)}{\pi^{*}}\left[W_{j}-C_{j}^{*}+(1-s)\left(P Q_{Y_{j}}-W_{j}\right)\right]=0, \\
& j=1, \ldots, l, \\
& \frac{\partial \hat{U}}{\partial Y_{j}}=\frac{\gamma s}{\pi}\left(P Q_{Y_{j}}-C_{j}^{*}\right)+\frac{(1-\gamma)(1-s)}{\pi^{*}}\left(P Q_{Y_{j}}-C_{j}^{*}\right)=0, \\
& j=l+1, \ldots, n \text {, } \\
& \frac{\partial \hat{U}}{\partial L}=\frac{\gamma s}{\pi}\left(P Q_{\mathrm{L}}-P_{\mathrm{L}}\right)+\frac{(1-\gamma)(1-s)}{\pi^{*}}\left(P Q_{\mathrm{L}}-P_{\mathrm{L}}\right)=0, \\
& \frac{\partial \hat{U}}{\partial V_{i}}=\frac{\gamma}{\pi}\left(X_{i}-s X_{i}\right)-\frac{(1-\gamma)(1-s)}{\pi^{*}} X_{i}=0, \quad i=1, \ldots, k \text {, } \\
& \Rightarrow \frac{\pi}{\pi^{*}}=\frac{\gamma}{1-\gamma}, \\
& \frac{\partial U}{\partial W_{i}}=\frac{-\gamma}{\pi} Y_{j}+\frac{(1-\gamma)}{\pi^{*}}\left[Y_{j}-(1-s) Y_{j}\right]=0, \quad j=1, \ldots, l, \\
& \Rightarrow \frac{\pi}{\pi^{*}}=\frac{\gamma}{1-\gamma} .
\end{aligned}
$$

Combining (A2), (A3), and (A7) yields

$$
P Q_{X_{i}}=C_{i}, \quad i=1, \ldots, m,
$$

which is the first condition in (5) of the main text. Conditions (A4), (A5), and (A7) lead to

$$
P Q_{Y_{j}}=C_{j}^{*}, \quad j=1, \ldots, n,
$$

which is the second condition in (5). Finally conditions (A6) and (A7) result in the criterion for the allocation of labor in (5): 


$$
P Q_{\mathrm{L}}=P_{\mathrm{L}} \text {. }
$$

From the equations for $\pi$ and $\pi^{*}$ it is possible to express $\pi^{*}$ as

$$
\begin{aligned}
\pi^{*}=\sum_{j=1}^{l}\left(W_{j}-C_{j}^{*}\right) Y_{j}+P Q-\sum_{i=1}^{k} V_{i} X_{i}-\sum_{i=k+1}^{m} C_{i} X_{i}-\sum_{j=1}^{l} W_{j} Y_{j} \\
-\sum_{j=l+1}^{n} C_{j}^{*} Y_{j}-P_{\mathrm{L}} L+\sum_{i=1}^{k}\left(V_{i}-C_{i}\right) X_{i}-\pi
\end{aligned}
$$

or

$$
\pi^{*}=P Q-C X-C^{*} Y-P_{\mathrm{L}} L-\pi .
$$

Upon substitution from (A7) this expression yields the distributional conditions in (5):

$$
\begin{aligned}
\pi & =\gamma\left(P Q-C X-C^{*} Y-P_{\mathrm{L}} L\right), \\
\pi^{*} & =(1-\gamma)\left(P Q-C X-C^{*} Y-P_{\mathrm{L}} L\right) .
\end{aligned}
$$

The strict concavity of the production function guarantees that the firstorder conditions correspond to a maximum.

\section{REFERENCES}

Balog, Nikola, and Varady, Tibor, Joint Ventures and Long-Term Economic Cooperation with Foreign Firms. Belgrad: Yugoslovenska Stvarnost, 1979.

Barnet, Richard, and Muller, Ronald E., Global Reach: The Power of the Multinational Corporations. New York: Simon \& Schuster, 1974.

Brada, Josef C., "Markets, Property Rights, and the Economics of Joint Ventures in Socialist Countries." J. Comp. Econ. 1(2):167-181, June 1977a.

Brada, Josef C., "Profit Maximization and Resource Utilization in the Transideological Enterprise." Riv. Internaz. Sci. Econ. Commerciali 24:442-453, 1977 b.

Bulgarian Law: Bulgarian Chamber of Commerce and Industry, "Decree for Economic Cooperations between Bulgarian Juridical Persons and Foreign Juridical and Physical Persons." Sophia, 1980.

Chinese Law: "The Law of the People's Republic of China on Joint Ventures Using Chinese and Foreign Investment-Adopted by the Second Session of the Fifth National People's Congress on July 1, 1979." Beijing Rev. 22, 29:July 20, 1979.

Domar, Evsey D., "The Soviet Collective Farm as a Producer Cooperative." Amer. Econ. Rev. 56:734-757, Sept. 1966.

Dymsza, William A., Multinational Business Strategy. New York: McGraw-Hill, 1972.

Fayerweather, John, International Business Strategy and Administration. Cambridge: Cambridge Univ. Press, 1976.

Hall, Robert E., and Lilien, David M., "Efficient Wage Bargains under Uncertain Supply and Demand." Amer. Econ. Rev. 69:868-879, Dec. 1979.

Hungarian Law: Hungarian Ministry of Finance, Decree No. 28 of 1972 (x. 3) pm and Decree No. 7 of 1977 V. 6, pl.

Hymer, Stephen, "The Efficiency (Contradictions) of Multinational Corporations." Amer. Econ. Rev., Proc., 60:441-448, May 1970.

Hymer, Stephen, The Multinational Corporation: A Radical Approach. Cambridge: Cambridge Univ. Press, 1979.

Laitinen, Kenneth, A Theory of a Multiproduct Firm. Amsterdam: North-Holland, 1980. 
Leontief, Wassily, "The Pure Theory of the Guaranteed Annual Wage Contract." J. Pol. Econ. 56:76-79, Feb. 1946.

Miyazaki, Hajime, and Neary, Hugh, “The Illyrian Firm Revisited." Mimeo., July 1979.

Nash, John F., Jr., "The Bargaining Problem." Econometrica 18: 155-162, April 1950.

Robinson, Joan, "The Soviet Collective Farm as a Producer Cooperative: Comment." Amer. Econ. Rev. 62:222-223, March 1967.

Romanian Law: Publicom, “Doing Business with Romania.” Bucharest: Foreign Trade Publicity Agency, 1979.

"Romanian Foreign Trade Law." Bucharest: Foreign Trade Publicity Agency, 1979.

Sapir, André, "A Growth Model for a Tenured-Labor-Managed Firm." Quart. J. Econ. 90:387 402, Nov. 1980.

Smith, Stephen C., "Joint Ventures between Multinational Corporations and the Third World: Bargaining Power and Development." Unpubl. manuscript, 1980.

Svejnar, Jan, "The Effect of Employee Participation in Management on Bargaining Power and Wages: A Generalized Nash Solution and Econometric Evidence from Germany." Working Paper No. 106, Industrial Relations Section, Princeton University, December 1977.

Svejnar, Jan, and Smith, Stephen C., "The Economics of Joint Ventures in Less Developed Countries." Working paper no. 254, Economics Department, Cornell University, June 1981.

Svejnar, Jan, "On the Theory of a Participatory Firm" J. Econ. Theory 26, April 1982.

Tomlinson, James, The Joint Venture Process in International Business. Cambridge, Mass.: MIT Press, 1970.

United Nations Economic and Social Council, Transnational Corporations in World Development: $A$ Re-Examination. New York: Litho in U. N., April, 1978.

United Nations Economic and Social Council, "Joint Venture Legislation in Eastern Europe and Yugoslavia: A Survey of Recent Developments, 1977-1979." April 29, 1980.

Vanek, Jaroslav, The General Theory of Labor-Managed Market Economies. Ithaca, N. Y.: Cornell Univ. Press, 1970.

Ward, Benjamin, "The Firm in Illyria: Market Syndicalism." Amer. Econ. Rev. 48:566-589, Sept. 1958.

Yugoslav Law: "Law on Investment of Resources of Foreign Persons in Domestic (Yugoslav) Organizations of Associated Labor (Law of Joint Ventures)." Official Gazette of the $S R F Y$, No. 18, Item 312, April 7, 1978. Unofficially translated by the U. S. Department of Commerce. 